\section{Letter to Editor in Response \\ to the Article Entitled \\ "Prospective Randomized \\ Trial of Ligasure \\ versus Harmonic \\ Hemostasis Technique \\ in Thyroidectomy" \\ by Rahbari R, et al in Ann \\ Surg Oncol DOI 10.1245/ \\ s10434-010-1161-6 \\ [Online November 12, 2010)}

\section{TO THE EDITORS:}

We read with interest the article by Rahbari et al. "Prospective Randomized Trial of Ligasure Versus Harmonic Hemostasis Technique in Thyroidectomy." 1 The article contributes useful information to the ever-growing technique of sutureless thyroidectomy. However, we have a few queries and comments to make.

Regarding the surgical technique, the surgeons choose to tie the vessel pedicles on the patient's side while the specimen side was divided with bipolar sealing system or ultrasonic coagulation device. May we know, what had been the standard practice of the authors? Were they using clips or ties on the specimen side and what was the operating room time of conventional thyroidectomy? What we feel is that while tying the knot might take more time, clips can be applied quickly on the specimen side and in that case there won't be any appreciable time difference between the conventional technique and the technique adopted by the authors. We also would like to know why the authors choose to tie on one side; most surgeons using these new coagulation/sealing devices now perform totally sutureless thyroidectomy. ${ }^{2}$
Comparing the operating time with conventional technique was not the primary goal of the article; however, it would still be worthwhile to know the time taken to perform thyroidectomy using conventional technique by the authors. Furthermore, the surgeon-wide distribution of operative procedure and neither the procedure-wide operative time (hemithyroidectomy vs. total thyroidectomy) were not mentioned; hence, it is unclear whether the nature of operative procedure had a bearing on the time taken by the individual surgeon. Although not significant, it is worthwhile to note that more patients in the Harmonic group underwent total thyroidectomy compared with the Ligasure group (57.8 vs. $35.6 \%$ ). Finally, we want to know whether drains were used, and if so, any difference in drainage volume observed between the Harmonic and Ligasure groups. ${ }^{3}$

Mayilvaganan Sabaretnam, MS, and Anjali Mishra, MS, PDC

Department of Endocrine Surgery, Sanjay Gandhi Postgraduate Institute of Medical Sciences, Raebareli Road, Lucknow, India

e-mail: anjali@sgpgi.ac.in

Published Online: 30 March 2011

(c) Society of Surgical Oncology 2011

DISCLOSURE The authors declare no conflict of any financial interests and did not receive grants from any commercial organizations.

\section{REFERENCES}

1. Rahbari R, Mathur A, Kitano M, Guerrero M, Shen WT, Duh QY, Clark OH, Kebebew E. Prospective randomized trial of Ligasure versus Harmonic hemostasis technique in thyroidectomy. Ann Surg Oncol. 2010. doi:10.1245/s10434-010-1161-6.

2. Chang LY, O’Neill C, Suliburk J, Sidhu S, Delbridge LH, Sywak M. Sutureless total thyroidectomy: a safe and cost-effective alternative. ANZ J Surg. 2010. doi:10.1111/j1445-2197.2010.05492.x.

3. Ecker T, Carvalho AL, Choe JH, Walosek G, Preuss KJ. Hemostasis in thyroid surgery: harmonic scalpel versus other techniques-a meta-analysis. Otolaryngol Head Neck Surg. 2010;143:17-25 